\title{
Reflexive Pronoun Deviations in Contemporary English Social Media
}

Gevorg Grigoryan Yerevan Brusov State University of Languages and Social Sciences

\begin{abstract}
The paper discusses reflexive pronoun deviations in modern English in the domain of social media. The mentioned deviations are the result of intensive contact of English with other languages. The advent of digital technologies make a platform for millions of speakers all over the world to communicate in any language they want. The latter has eventually triggered the convergence of many grammatical structures and lexical items of different languages. As a result, new deviations and misspellings emerge in different platforms of social media. Among these alterations, the actively used reflexive pronoun misspellings and variations have a unique role. These pronominal variations help us to evaluate the current state of reflexive pronouns and lead us to foresee the possible future change of English.
\end{abstract}

Key words: language contact, social media, pronominal irregularities, reflexive pronoun fusions, linguistic deviations and errors.

\section{Introduction}

Everything in this universe is perpetually in a state of change (Aitcheson 1991:3). Over time, languages also change to meet the needs of society. There seem to be different reasons of language change. Languages may undergo deep changes due to immigration, new technologies, trade, political and economical pressure, colonization, cultural imperialism, etc. (Boeschoten and Johanson 2008:25). The latter may have a wide variety of outcomes. On the one hand, the intensive contact with other languages does trigger the development of grammatical and lexical structures in a number of ways. On the other hand, it is 
the source of new vocabulary, which enriches the language. In this regard, it is worth mentioning that the contact of people speaking different languages was not too active until the $21^{\text {st }}$ century. Language boundaries were distinctly preserved which was determined by poor technologies of telecommunications.

However, with the advent of digital technologies the contact gradually has increased. This has eventually led to the emergence of social media. Today social media have become an integral part of everyday communication. Different platforms of social media enjoy more and more popularity because millions of people from different parts of the world take part in various discussions in chat groups, discussion boards and forums. People with different linguistic backgrounds find themselves interacting in different social sites, blogs, discussion boards, etc. As stated by Reitz (2012:44) social media have changed the nature of everyday communication by providing a platform for individuals and organizations alike to engage with each other in a dynamic, synchronized, and multidirectional dialogue that represents varied voices.

Due to the economic and political power of the USA and Great Britain, English is considered to be the most prevalent language of social media. Hence, there has been an expansion in the number of English speakers all over the world. Today the English language is in deep contact with many genetically related and unrelated languages worldwide. It is important to note, that in a way the future development of English is determined by contact with other languages, because the content on different platforms of social media is often generated in two languages simultaneously. An illustration of the above stated is the following examples taken from different social sites (facebook, twitter, flickr, etc):

Feliz Cumpleanos my Dear Amiga hope u are having an amazing day...May God bless u always (facebook)

\#Empleo \#Job I would like to hire by CastorMorgan: Nous sommes à la recherche d'un rédacteur en free pour le... (twitter) 
Sorry it's late but hope your birthday was beautiful just like u mi AmigaCorena Torrez!!! Feliz CUMPLEANOS mamita! Love $u$ (facebook)

Je sais Nous sommes inconnus beyond the borderline of social media I would like and $i$ wanted to be a friend.

(twitter)

CONGRATULATIONS a todos nuestros alumnos del B1. Un año más hemos vuelto a conseguir el 100\% de aprobados gracias avosotros. THANK U!

(facebook)

As the above examples illustrate, some components of the sentences are in English, whereas others are in foreign languages: Spanish, French, etc. which in a way are in close contact with English. In this respect, it is worth stressing the fact that in the domain of online interaction it is not necessary to transmit coherent lexical-grammatical sentences and items.

Speakers with different linguistic backgrounds combine grammatical and lexical elements of their native language with the English ones. Speakers make a wide use of lexical units, which are combinations of two different languages, for example, unoself, laself, nousself, toiself and so forth.

It can be noted that social media is full of fusions of two source languages. The lexical innovations are not considered to be an indication of illiteracy. In virtual environment lexical mixtures and bilingual deviations are the result of spontaneity.

Bilinguals frequently make use of lexical fusions of two source languages, which are more common in everyday talks. Many studies show that in modern English the list of high-frequency words involve mainly function words, and includes pronouns, articles, prepositions, etc. According to C. Chung and J. Pennebaker (2007:347) function words have a powerful impact on the listener/reader and, at the same time, reflect a great deal about the speaker/writer. Hence, it is not surprising that pronominal fusions of two source languages are rapidly evolving in various platforms of social media. Among these pronominal fusions are the reflexive pronoun mixtures found in contemporary English social media. 


\section{Reflexive Pronoun Fusions}

According to the surveys carried out in social media reflexive pronoun fusions mainly include items from Spanish. It is not accidental, because the flow of Spanish-speaking immigrants has undoubtedly increased in the USA in the last ten years. Spanish speakers replace the first component of reflexive pronouns, i.e. the object and possessive pronouns, whereas the second stem self - remains constant. An illustration of the above stated are the following examples:

Get tuself down to le@walkerartcenter for le 2015 Internet Cat Video Festiva! (twitter)

HE IS THE WAY THE TRUE N THE LIGHT. NO ONE COMMEND TO THE FATHER ELSELF THRONG HIM

(facebook)

... ugghhhh... neck and shoulders $r$ killing me from the anger. ....the chick at $k f$ better be nice... orelself.. she wont be to lucky...

(facebook)

Bank holiday weekend with @ellaself (twitter)

Be yoself no matter Wat. Some wil adore $u$, while others wil hate eveytin abot $u$

(facebook)

Kip yoselfin a position wea $u$ hear God, u must prepare yoself $b 4$ any situations ever emerge

(facebook)

TOTALLY MADE TIHS MISELF (reddit)

Comin ovr from /r/pcfaggotrace $i$ thougt the enhanced graphicz wher a bit hard 2 reed, got miself a pear of these and im good tooo go!!!!!!11!!!

You're overlooking the pleasure in cooking tiself, not just eating

Love loself (twitter)

LaSelf love .... when nobody cares n u just smile a lil... (facebook)

So uno could keep uno corrupted religion to unoself.....cause $i$ good with my God

(facebook) 
This fi happen to some a uno pussyhole that caah commit unoself to a trying youth who would shower uno dung wid love and have sleepless nights fi ensure uno alrite (facebook)

make una no dey call unaself fool anyhow jare, you should know that was a typo

(twitter)

Fighting bcos of a BOY!!! Mak una kill unasselves na... (facebook)

In many social sites like facebook, twitter, myspace, tumblr, flickr, etc. reflexive pronoun mixtures with French and Italian can also be found. However, it should be noted that the users do not actively utilize these pronominal fusions in comparison with the Spanish ones:

Awesome sushi's fait nousself

(twitter)

Be happy and be nice to toiself and treat your shadow well...

(flickr)

@Zoe_Ashdown -- of the drink. It was perfect and warming for the early afternoon's chill.\} So, tell moi about vousself,

(facebook)

@natrevrover was supposed to be doing that with Elleself, but lack of work curtailed that plan, even got it booked last July

(twitter)

\#ILself continua con una ghiotta segnalazione: ben due romanzi, di Silvia Devitofrancesco: l'umoristico ULTIMO... (facebook)

Paroli is sposting luiself to Verdini? \#shish ... (twitter)

gonna explore by Moiself. be back in a number of hours!

(twitter)

Be Toiself (facebook)

qui peuvent jamais être heureuse pour les autres ptn mais Go floatez vosself (twitter)

\#TBTw/pretty_live_girl@yup_itspoe quiself_made we turnt in Miami's http://instagram.com/p/jhB8fLn3_m/

(twitter) 
Witout God, my un!queself $d z$ nt exist, Witout God my sense of being doz not hav meaning.. I AM BCOZ HE IS..1\#mornin tweeps,blessed week ahead (twitter)

$@$ @ESelf now that's an embarrassment (facebook)

@hettienne qui/quis/quiself (pronounce key/kwee based on preference/origin) (twitter)

$@$ @eEmoBurrito well $i$ was about to tweet dat but no (i regret mienself) (twitter)

there's a picture on instagram of my crush..... and in the background..,,, i'm looked at him.,.. im choked mienself (twitter)

Interestingly enough, the substitution of the first item in English reflexive pronouns with the French, Spanish and Italian ones is not reasonable. The replacement of foreign elements is arbitrary. As the examples show, bilingual speakers can substitute the first item with any type of French, Spanish, Italian pronouns: personal, possessive, indefinite, interrogative, etc.

In modern English reflexive pronouns end in self or selves, which refer to singular and plural forms. However, it is relevant to note that in certain cases the formations of reflexive pronouns in two source languages are reflected with the addition of foreign suffixes like fita, lo, vo, etc. which are equally employed both for singular and plural forms:

okej qika gjeremika imma go sleepita myselfita

(twitter)

What kinda chance does this jazz freak have with a foxy whockachahcha cheeqa like yourselvo (facebook)

$r A$ person's wth in this world is estimated according to the value they put on themselvo. -Jean De La Bruyere (twitter)

@BrandonLorenzo You know there's something wrong when you start sending tweets to yoursello there. Yummy. ;) (twitter)

Free yoursello (twitter)

Hopefully Healthy And Be A Good Boy MySello (facebook) 


\section{Manaña es el reto.......leandro y hersello ...presente del club CLUB TAEKWONDO TITO INCA http://fb.me/2n5JwiZBL}

(twitter)

The keeper personally provided oursello (caminotime blogspot)

Thus, one can assume that the homogenization of singular and plural endings eases the communication in the domain of online environment and leads the English language to have simplified grammatical structures.

\section{Linguistic Interference as the Basis of Reflexive Pronoun Irregularities}

In contemporary English social media many errors of reflexive pronouns occur as a result of linguistic interference. According to Weinreich (2011:27), instances of deviation from the norms of either language occur in the speech of bilinguals as a result of their familiarity with more than one language, i.e. as a result of language contact. In the domain of online communication, speakers employ the English language in accordance to their mother tongue, which results the rise of errors. Many languages speakers frequently make use of verbs which often employ reflexive pronouns like German sich anziehen - get dressed, sich erholen - get better, French se lever - get up, se doucher - have a shower, se promener - have a walk, Italian alzarsi - get up, combiarsi - change clothes, etc. In comparison to the mentioned foreign languages, in English reflexive verbs are used much less often. In fact, modern English lacks pronominal verbs. However, one can easily note that in online interactions bilingual speakers often violate the rules and add reflexive pronouns to verbs which are not necessary used with reflexive pronouns:

I get myself up, shower myself and have breakfast before I leave for work

(thoughtco)

She becomes herself angry when she doesn't get her way

(thoughtco)

My Husband Dressed Me For a Week, and It Changed the Way I Dress Myself

(twitter) 
Been in bed snoozing my alarm for an hour and a half because $I$ just can't make myself get up. Depression is fun (twitter)

The overuse of reflexives as the result of foreign language interference has become so widespread today that many English online teaching websites such as <www.britishcouncil.com>, <www.engivid.com>, <www.thoughtco.com>, etc. have already included it in the list of common mistakes made by bilingual speakers.

As a result of the mentioned linguistic influences, gradually a new type of verbs emerges in modern English. Speakers delete the first component of reflexive pronouns and merge the stem self with verbs, like in doeself, makeself, listenself.

These innovative formations are written together without any hyphen. In different platforms of social media speakers make use of this kind of verbs in order to emphasize that they are acting upon themselves. Interestingly enough, today there is a rapid growth of these newly formed verbs. Here are some examples taken from twitter:

Im Supposed To DoSelf Administered Allergy Shots Every Other Day But I Be Forgetting

\#BMCPolls2017 it's lesson to shivsena forget dirty politics and think for all who live in Maharashtra and doself assessment of your workpast

ok i gtg washself brb kisses

Right off to washself then sleep

He knows that it's not all about the handsome image, and he always makesELF laugh with his derpy faces

when $i$ was younger, $i$ would makeself a time frame to get home before 3-4 because zoey 101 was on until late lol

I know how you feelself

Feelself like a looooooooooseer 
Good probably all communist democrats. Actually they are the communist liberals and blames other party for Russia hack they need to lookself

Irregularities also occur because of the lack of gender differentiation in the third person plural form. As it is known, in many languages plural reflexive pronouns are clearly distinguished into male, female and neutral, whereas in modern English the gender distinction of reflexive pronouns is only bound in singular form. The plural reflexive third person is neuter. There is no clear-cut distinction of it, that is why bilingual speakers often make use of reflexive pronoun innovations which are in a way quite awkward for Standard English: himselves, itselves, herselves, shesselves, hesselves, itselves. The examples below are taken from the twitter:

\section{hes don't love hesselves}

ISIS refuses all idea of Democracy, it searchs to break up the unity, solidarity, the precepts, concepts itselves of Democracy in everybody

Arie \& Stephanie will straighten it out they don't take no Crap and let the aholes.make a complete fool out of his or herselves

it's unfair to sheselves to keep them in prison for such a wretched offense.\#tcot Reading hate comments that haters send to @Khairykj regarding this flag issues, is too hurtful for Abah and Malaysian itselves! \#KL2017

Beautiful Blonde Feeling Lonely Fingers Herselves

"We can defend those who cant defend himselves" Você disse Teen Wolf? Não, pera, é GoT

No need other peoples. we are himselves rule until the day of judgement. We are brave nation among all over the world. thanks for ur opinion 
Thus, one can see that in the domain of online communication bilingual speakers try to find out the equivalent forms in English, then the lack of proficiency make them create pronominal innovations on their own.

The next deviation that we have noted for reflexive pronouns in contemporary English social media is the conversion of the position. In modern English the word order is rigidly fixed and canonical. For example, reflexive pronouns are used after verbs. However, in their posts English speakers make use of reflexive pronouns before predicates to add emphasis and intensify their statements. The following examples are taken from gingersoftware:

Jesse wondered aloud whether he himself was the only one seeing what was happening

Maria knew that she herself could make a positive impact on the world, if only she put her mind to it

You yourself can easily transform your body: All it takes is a proper diet and plenty of exercise

A thorough investigation carried out in different platforms of social media reveals that there is a growth of conversion of reflexive pronouns in speakers' posts. We hasten to add that it has nothing to do with the intensification and emphasis. To prove the above stated let us compare reflexive pronoun positions in Italian, French and Spanish. In French, for example, reflexive pronouns are positioned in front of the verb - predicate in nearly all tenses and moods. The following examples are taken from thoughtco:

Nous nous parlons.

Ils ne s'habillent pas
We're talking to each other.

They aren't getting dressed

In modern Italian as well, reflexive pronouns are placed before a conjugated verb or predicate like in the examples below (taken from thoughtco):

Si lava tutti i giorni.
He washes himself every day. 
Ci divertiamo molto qui. We enjoy ourselves a lot here.

A casa, m’annoio.

At home, I get bored.

In modern Spanish reflexive pronouns are placed before conjugated verbs as well. The following examples are taken from spanishdict:

Me ducho cade manana.

Tu peinas antes de salir.

Se hablaba.
I shower every morning.

You brush your hair before going out.

He was talking to himself.

Consequences follow that in English the growth of usage of reflexive pronouns in place before conjugated verbs is the result of language contact as well. The following examples are the illustration of the above stated:

I myself run a $B \& B$... a lot to learn from this experience ... a truly traditional Indian family experience full of warmth \& smiles ....

(tripadvisor)

I myself don't like this idea. (english.stackexchange)

I myself believe that natural medicines like medical marijuana beat out traditional prescription drugs any day.

(facebook)

I, myself, have killed six people. All random, all undetected, no way to trace them to me.

(goodreads)

We ourselves feel that what we are doing is just a drop in the ocean.

(brainy quote)

In modern English grammar it is accepted to use reflexive pronouns when the subject of the sentence and the object of the sentence are the same, however, today one can find many deviations of these rules. The latter can be explained in accordance with linguistic interference as well.

She continued to stare at his scars. He shook herself out of it and looked back up at his face "Wow...

(twitter) 
--before blinking and twitching her nose like a little rabbit would. "Wait... why am I getting taller?" she asked as he looked at herself. (twitter)

It's a good thing. He really protected myself and Luke while we were growing up, and sable was pretty chill too.

(twitter)

You may submit your expenses to myself before Friday.

(grammarly)

$i^{\prime}$ ve been up and stare at herself as shit.

(twitter)

$i$ just woke up and stare at herself in the morning \#enstars \#あんさんぶるスター (twitter)

Your wcw comes to the gym just to stare at herself in the mirrors, it's me I'm your wcw.

(twitter)

Thorough surveys in social media show that there develops a new linguistic feature which is not peculiar to modern English. Generally, like object pronouns, reflexive pronouns are placed before the verb in imperative as well. However, in recent years there is a tendency which evolves to attach the reflexive pronouns at the end of the verb with a hyphen, like in the following examples from the twitter:

A "real" can Do It-Yourself Home Improvement... on Steroids.

Graffiti Removal Guys Complete "Do-It-Yourself kit" (Sensitive Surfaces)Gr...via @amazon.

A MUST DO...IT-YOURSELF for our mamas! Suction cup bowls... Perfect for our messy monsters...and...

Many people will tell $U$ dat $U$ can't make it,neva be fooled, there is someone that strongly believe U can make IT-YOURSELF

I posted 10 photos on Facebook in the album "Macy's Make-ityourself Galore!"

In French two subtypes of reflexive pronouns are distinguished: weak and strong. In imperative forms strong reflexive pronouns are attached to the end of 
the verb with a hyphen like in leve-toi, aidons-nous, etc. This means the existence of this kind of linguistic deviation can be explained by the deep influence of the French language.

\section{Conclusion}

To sum up the survey carried out in the present paper, we can say that contemporary English social media play an important and unique role in everyday communication because they stimulate exchanges of information and creation of a simple and quick communicative platform where information dissemination is easily distributed to speakers with different linguistic background. The active use of words by bilinguals make an efficient ground for different linguistic deviations and variations. Among these variations, English reflexive pronouns should be mentioned. The intensive contact of many languages triggers the rise of reflexive pronoun deviations, which are noted in all levels of the English language. Over time pronominal deviations have the tendency to become a linguistic norm and this may lead the English language to changes.

\section{References:}

1. Aitcheson, L. (1991) Language Change: Progress or Decay?Cambridge: CUP.

2. Chung, C.; Pennebaker, J. (2007) The Psychological Functions of Function Words. // Social Communication. New York: Psychology Press.

3. Crystal, D. (2008). Txting: The gr8 db8. Oxford: OUP.

4. Boeschoten, H.; Johanson, L. (2008) Turkic Languages in Contact. // Wiesbaden: Harrazowitz Verlag.

5. Reitz, A. (2012) Social Media's Function in Organizations: A Functional Analysis Approach. // Global Media Journal. Vol. 5. Ottawa: University of Ottawa Press. 


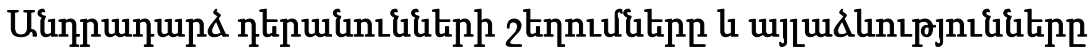

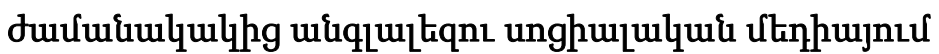

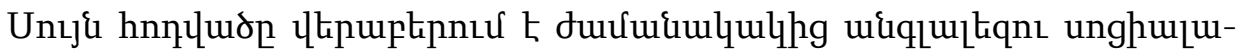

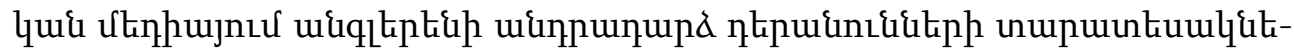

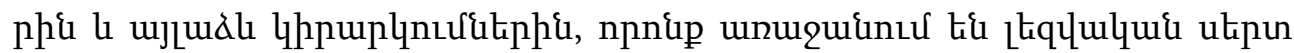

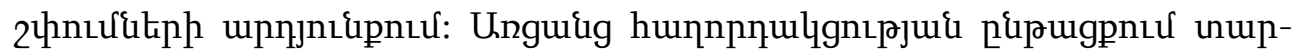

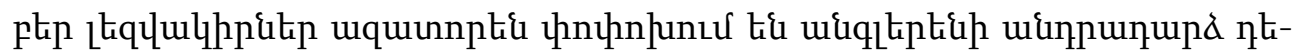

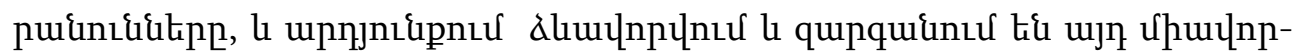

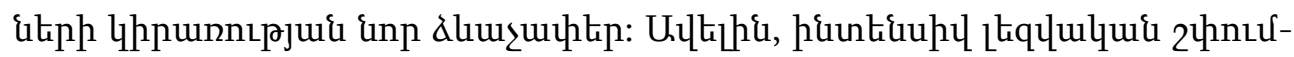

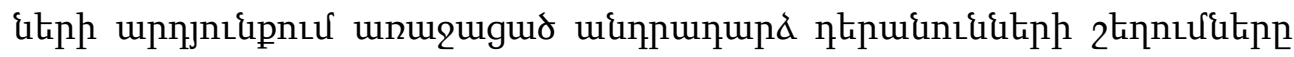

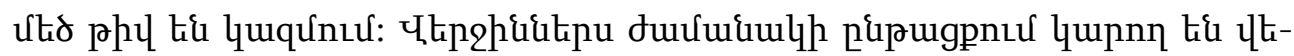

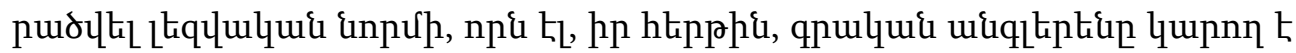

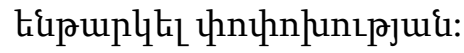

